\title{
Anti-tumor immunity elicited by cross-linking vaccine heat shock protein 72 and alpha-fetoprotein epitope peptide
}

\author{
Z. $\mathrm{LI}^{1,2}$, X. P. WANG ${ }^{2, *}$, H. P. $\mathrm{LIN}^{2}$, B. XU' ${ }^{2}$, Q. ZHAO ${ }^{2}$, B. N. QI ${ }^{2}$, Y. X. YANG ${ }^{3}$, Z. R. WANG ${ }^{1, *}$
}

${ }^{1}$ Department of Traditional Chinese Medicine, Xijing Hospital, Fourth Military Medical University, Xian, PR China; ${ }^{2}$ Laboratory of Molecular Biology \& Pathology, Shaanxi University of Chinese Medicine, Xianyang, PR China; ${ }^{3}$ Department of Biological Sciences, Emporia State University, Emporia, USA

*Correspondence: wxpphd72@yahoo.com,yanfengyun2011@126.com

Received September 28, 2014 / Accepted March 18, 2015

\begin{abstract}
Hepatocellular carcinoma (HCC) is one of the most common malignancies over the world. Alpha-fetoprotein (AFP) is an oncofetal protein during HCC development, which could generate weaker and less reproducible antitumor protection, and may serve as a target for immunotherapy. Therefore, it is imperative to enhance its immunogenicity and develop therapeutic vaccines to eliminate AFP-expressing tumors. In this study, by using glutaraldehyde cross-linking, we constructed a potential therapeutic peptide vaccine, heat shock protein 72 (HSP72) and AFP epitope peptide (HSP72/AFP-P). ELISPOT was applied to evaluate the quantity of AFP-specific $\mathrm{CD} 8^{+} \mathrm{T}$ cell that secreted IFN- $\gamma$ in immunized BALB/C mice. Granzyme $\mathrm{B}$ released from natural killer cells and AFP-specific antibody responses in immunized mice were detected by ELISA. The anti-tumor effects were investigated by in vitro cytotoxic T-lymphocyte assays and in vivo tumor therapeutic experiments. The results showed that reconstructed HSP72 and AFP epitope peptide vaccine synergistically exhibited significant increases in AFP-specific $\mathrm{CD} 8^{+} \mathrm{T}$ cells, natural killer cells responses and impressive antitumor effects against AFP-expressing tumors. Immunization of BALB/C mice with HSP72/AFP-P vaccine elicited stronger T-cells responses. The numbers of IFN- $\gamma$ producing $\mathrm{CD}^{+} \mathrm{T}$ cells from mice immunized with HSP72/AFP-P were 30 times more than those from mice immunized with AFP-P, HSP72 or PBS $(P<0.01)$. The concentration of granzyme B in natural killer cells from mice immunized with HSP72/AFP-P were 15 times higher than that from other groups $(P<0.01)$. In vitro effector cells from mice immunized with HSP72/AFP-P showed much stronger cytolytic effect on $\mathrm{H} 22$ target cells than those from mice vaccinated with AFP-P, HSP72 or PBS $(P<0.01)$. Priming mice with the reconstructed vaccine exhibited robust strong protective immunity. Mice immunized with HSP72 or AFP-P alone demonstrated higher average tumor volumes than mice immunized with HSP72/ AFP-P $(P<0.05)$. Our study suggests that constructing a tumor vaccine by cross-linking AFP antigen epitope peptide and HSP72 is a promising approach for cancer therapy.
\end{abstract}

Key words: alpha-fetoprotein (AFP), antigen epitope, cytotoxicity, heat shock protein 72 (HSP72), hepatocellular carcinoma (HCC), immunity

Hepatocellular carcinoma (HCC) is one of the most common malignancies over the world and accounts for as many as 1.2 million deaths annually [1]. It is rising rapidly in China because of hepatitis B and C infections [1,2]. Although surgery and liver transplantation are effective therapies, most patients still lose chance due to diagnosis at a late stage or underlying liver insufficiency in the setting of cirrhosis [3]. Therefore, it is imperative to develop new therapeutic approaches to improve survival time and life quality of HCC patients.

In the recent years, therapeutic vaccine, which aims to manipulate and enhance the host's immune system to elicit potent antigen-specific responses to the tumors, has drawn increasing attention. About $80 \%$ of HCC have a high expressing of alpha-fetoprotein (AFP), which may serve as a target for immunotherapy $[3,4]$. AFP is an oncofetal protein during HCC development which could generate weaker and poorly reproducible antitumor protection [5]. Therefore, a vaccine specifically targeting AFP is particularly desirable. Many therapeutic strategies that enhance the pre-existing antitumor immunity have been evaluated, including recombinant proteins, peptides, plasmid DNA, chimeric virus-like particles, viral or bacterial vectors expressing AFP proteins and 
adoptive transfer of tumor-specific T cells [4-11]. However, therapeutic vaccination has been restricted by inadequate antigen-specific immune responses. Therefore, strategies to develop more effective antigen specific immune responses need to be thoroughly explored.

Heat shock proteins (HSP) have been verified to act as potent immunoadjuvants to enhance antigen-specific tumor immunity [12]. HSP play an important role not only in the process of protein folding, transport and degradation, but also in participating in directing more efficient antigen presentation to $\mathrm{CD} 8^{+} \mathrm{T}$ cells through the MHC-I pathway [12]. This central role of HSP in therapeutic vaccine is facilitated by their dual functions in both chaperoning antigens and serving as an adjuvant. HSP are classified into families according to their size, structure and function, including small HSP, HSP60, HSP70, HSP90, gp96 and calreticulin (CRT). They have different structures that are adapted to different immunoadjuvant functions $[12,13]$. Specifically, HSP90 and HSP70, the most abundant cytosolic chaperones, have been proposed to transport peptides to the heterodimeric transporters associated with antigen processing $[13,14]$. Furthermore, HSP-based tumor vaccine strategies have been highly successful in animal models and are undergoing testing in clinical trial $[10,15,16]$. Therefore, an innovative approach that combines with families of HSP will be likely to generate more potent antitumor effect.

In the present study, we investigated whether the immunogenicity of AFP peptide containing antigen epitope FMNKFIYEI, could be improved by HSP72 molecules and whether HSP72 could synergistically enhance the capacity of AFP peptide therapeutic effect. We constructed a peptide vaccine containing the molecule chaperon-HSP72 and AFP antigen epitope by way of glutaraldehyde cross-linking. Our results demonstrated that AFP peptide and HSP72 synergistically exhibited significant increases in AFP-specific CD8 ${ }^{+}$ $\mathrm{T}$ cells, natural killer cell responses by impressive antitumor effects against AFP-expressing tumors. Primimg mice with the reconstructed vaccine, we elicited strong protective immunity. Therefore, cross-linking HSP72/AFP peptide may generate a novel tumor vaccine that is promising for treating hepatocellular carcinoma through a combination of antigenspecific immunotherapy.

\section{Materials and methods}

Mice and tumor cell lines. Six- to eight-week-old female $\mathrm{BALB} / \mathrm{C}$ mice were purchased from the Experimental Animal Center at Fourth Military Medical University. All animals were maintained under specific-pathogen-free conditions, and all procedures were performed according to approved protocols and in accordance with recommendations for the proper care of laboratory animals. The investigation was approved by the Ethics Committee on Animal Study at Shaanxi University of Chinese Medicine (2004-4B). mAFP-producing H22 mice hepatocellular carcinoma cells were kindly provided by College of Biomedicine, Xian Jiaotong University and maintained in
RPMI 1640 (Gibco-BRL, USA) with 10\% fetal bovine serum, $100 \mathrm{U} / \mathrm{ml}$ penicillin, and $100 \mu \mathrm{g} / \mathrm{ml}$ streptomycin (Invitrogen Corp., CA, USA) at $37^{\circ} \mathrm{C}$ under humidified atmosphere of 95\% air and 5\% $\mathrm{CO}_{2}$. Lewis lung carcinoma (LLC) cells were purchased from Institute of Biochemistry and Cell Biology of Chinese Academy of Sciences and cultured in DMEM (GibcoBRL, USA) with $10 \%$ fetal bovine serum at $37^{\circ} \mathrm{C}$ in $5 \% \mathrm{CO}_{2}$.

AFP peptide, HSP72 and conjugation. Mouse AFP peptide containing epitope 158-166 amino acid, FMNKFIYEI, was synthesized from the ZiYuPeptides Co., Ltd (Shanghai, China). Lyophilized material was resuspended in sterile distilled water at $10 \mathrm{mg} / \mathrm{ml}$, aliquoted, and stored at $-70{ }^{\circ} \mathrm{C}$ until use.

Mouse heat shock protein 72 (HSP72) expressing Escherichia coli strain was provided by Dr. X. Sun in North Dakota State University in the U.S. The HSP72 expression vector contained an IPTG-inducible T7 promoter and was in frame with the C-terminal 6-His-tag (Invitrogen Corp., CA, U.S.A.). E. coli cells transformed with the plasmid were grown until the OD reached at 0.5 , and then IPTG $(1 \mathrm{mM}$ final concentration) was added. After induction with IPTG at $37^{\circ} \mathrm{C}$ for $3 \mathrm{~h}$, cells were disrupted by sonication in a lysis buffer containing a nonionic detergent and lysozyme. Recombinant HSP72 protein was purified using nickel nitriloacetic acid (Ni-NTA)-agarose (Qiagen, Valencia, CA, U.S.A.) column. Protein purity was assessed using sodium dodecyl sulfatepolyacrylamide gel electrophoresis (SDS-PAGE) stained with Coomassie blue. The identity of the purified protein was verified by Western blotting with a polyclonal antibody (Santa Cruz Biotechnology Inc., Santa Cruz, CA, U.S.A.). Protein concentration was determined using BCATM protein assay kit (Pierce Inc., Rockford, IL, U.S.A.).

One milligram AFP peptide was coupled to $1 \mathrm{mg}$ HSP72 in the presence of $0.2 \%$ glutaraldehyde in phosphate buffer saline (PBS) for $2 \mathrm{~h}$, and then dialyzed against PBS overnight. Aliquots of each conjugate were stored at $-70{ }^{\circ} \mathrm{C}$ until use.

Purification and Western blot analysis. The HSP72/AFP peptide cross-linking vaccine (HSP72/AFP-P) was purified by HSP72 polyclonal antibody-affinity chromatography and AFP polyclonal antibody-affinity chromatography sequentially. Protein purity was assessed using sodium dodecyl sulfatepolyacrylamide gel electrophoresis (SDS-PAGE) stained with Coomassie blue. The identity of the purified protein was verified by Western blot with polyclonal antibodies (Santa Cruz Biotechnology Inc., Santa Cruz, CA, U.S.A.). Protein concentration was determined using BCATM protein assay kit (Pierce Inc., Rockford, IL, U.S.A.).

After centrifugation, the purified protein complex was denatured with SDS sample buffer $(62.5 \mathrm{mmol} / \mathrm{L}$ Tris- $\mathrm{HCL}, \mathrm{pH}$ 6.8, $25 \mathrm{~g} / \mathrm{L}$ SDS, $50 \mathrm{ml} / \mathrm{L} \beta$-mercaptoethanol, $100 \mathrm{ml} / \mathrm{L}$ glycerol) at $100^{\circ} \mathrm{C}$ for $5 \mathrm{~min}$. The purified protein complexes were then analyzed by $90 \mathrm{~g} / \mathrm{L}$ SDS-polyacrylamide gel electrophoresis (SDS-PAGE). Proteins were transferred to nitrocellulose (NC) membrane (Bio-Rad) and detected by immunoblotting with HSP72 rabbit anti-mouse polyclonal antibody (1:100) 
or AFP rabbit anti-mouse polyclonal antibody (1:100) at 4 ${ }^{\circ} \mathrm{C}$ overnight, respectively. After a thorough wash in PBS, the membranes were treated with horseradish peroxidase-labeled goat anti-rabbit antibody $(1: 100)$ for $45 \mathrm{~min}$ at $37^{\circ} \mathrm{C}$. After a complete wash in PBS, the membranes were developed in 0.5 $\mathrm{g} / \mathrm{L}$ freshly prepared 3, 3'-diaminobenzedine solution (DAB, Sigma, U.S.A.) for $8 \mathrm{~min}$. $\beta$-actin was used as a negative control and the internal reference.

Mice immunized with HSP72/AFP-P complex. Female BALB/C mice were randomly divided into HSP72/AFP-P group, AFP-P group, HSP72 group, PBS control and empty group. Every group had 10 mice. Before injection, each antigen was diluted in saline to the concentration of $100 \mu \mathrm{g} / 100 \mu \mathrm{l}$. Each antigen was injected into the left flank of mice subcutaneously (s.c.). Priming and boosting was performed with $10 \mu \mathrm{g}$ HSP72/ AFP-P, AFP-P or HSP72, whereas PBS was used as controls. A 0.3 insulin syringe with a 25 -gauge 0.5 -inch-long needle was used for the s.c. injections. Mice were boosted s.c. with above proteins twice at 2 -week intervals after the first priming. Two weeks after last immunization, splenocytes were harvested and diluted to different concentrations.

Enrichment of $\mathrm{CD8}^{+} \mathrm{T}$ cells and natural killer cells from murine splenocytes by MACS-microbead selection. To isolate $\mathrm{CD} 8^{+} \mathrm{T}$ cells and natural killer cells from splenocytes harvested from above immunized mice, $\mathrm{CD}^{+} \mathrm{T}$ cells and natural killer cells microbead kit (Miltenyi Biotec, Bergisch Gladbach, Germany) was used. CD8 ${ }^{+} \mathrm{T}$ cells or natural killer cells from splenocytes captured on antiboy-coated magnetic beads was recovered from the magnetic column by eluting with Tris Buffered Saline (TBS) as described by the manufacturer (MS column, Miltenyi Biotec, Bergisch Gladbach, Germany). $\mathrm{CD}^{+} \mathrm{T}$ cells or natural killer cells-coated beads were pelleted by centrifugation at $1,000 \mathrm{~g}$ for $10 \mathrm{~min}$. The captured cells were cultured in RPMI 1640 (Gibco-BRL, USA) with 10\% fetal bovine serum, $100 \mathrm{U} / \mathrm{ml}$ penicillin, and $100 \mu \mathrm{g} / \mathrm{ml}$ streptomycin (Invitrogen Corp., CA, U.S.A.) at $37{ }^{\circ} \mathrm{C}$ under humidified atmosphere of $95 \%$ air and $5 \% \mathrm{CO}_{2}$.

ELISPOT assay. ELISPOT was used to measure the frequency of cells producing the cytokine IFN- $\gamma$ in $\mathrm{CD} 8^{+} \mathrm{T}$ cells captured from above immunized mice. BD ELISPOT Plates (BD PharMingen, San Diego, CA, USA) were coated with 5 $\mu \mathrm{g} / \mathrm{ml}$ rat anti-mouse IFN- $\gamma$ antibody in $100 \mu \mathrm{l}$ of PBS. After overnight incubation at $4{ }^{\circ} \mathrm{C}$, the wells were washed and blocked with RPMI-1640 culture medium containing $10 \%$ fetal bovine serum. $1 \times 10^{6} \mathrm{CD} 8^{+} \mathrm{T}$ cells were added to the ELISPOT plate wells along with $5 \mu \mathrm{g} / \mathrm{ml}$ of AFP peptide containing $10 \%$ fetal bovine serum, 10 units $/ \mathrm{ml}$ of mouse interleukin (IL)-2 (PEPRO Tech ET Ltd.). After culturing at $37^{\circ} \mathrm{C}$ for $24 \mathrm{~h}$, the plate was washed and then incubated with $2.5 \mu \mathrm{g} / \mathrm{ml}$ biotinylated IFN- $\gamma$ antibody in $100 \mu \mathrm{l}$ PBS containing 10\% FCS at $4^{\circ} \mathrm{C}$ overnight. After washing, avidin-HRP in $100 \mu \mathrm{l}$ PBS was added and incubated for $1 \mathrm{~h}$ at room temperature. After washing five times, spots were developed by adding $100 \mu \mathrm{l}$ 5-bromo-4-chloro-3-indolyl phosphatase/Nitro Blue Tetrazolium (Boehringer Mannheim, Indianapolis, IN, U.S.A.).
The color spots, representing cytokine producing cells, were counted using an ELISPOT Reader System.

ELISA assay. To determine the level of anti-AFP antibody and anti-HSP72 antibody in mice, we examined the serum from mice tail vein after the last immunization by ELISA. A 96-well microplate was coated with $100 \mu \mathrm{l}$ of $5 \mu \mathrm{g} / \mathrm{ml} \mathrm{AFP}$ peptide or HSP72 purified protein and incubated at $4{ }^{\circ} \mathrm{C}$ overnight. The wells were then blocked with PBS containing $5 \%$ BSA. Sera from the mice were prepared on day 14 postimmunization, serially diluted in PBS, added to the ELISA wells and incubated at room temperature for $2 \mathrm{~h}$. After washing with PBS-T containing $0.05 \%$ Tween-20, the plate was incubated with 1:3000 dilution of a HRP-conjugated goat anti-mouse IgG antibody (Sigma-Aldrich Corp., St Louis, MO, U.S.A.) at room temperature for $1 \mathrm{~h}$. The plate was washed five times, developed with O-phenylenediamine away from light at $37^{\circ} \mathrm{C}$ for $15 \mathrm{~min}$ and stopped with $50 \mu \mathrm{l}$ of $2 \mathrm{M} \mathrm{H}_{2} \mathrm{SO}_{4}$. The ELISA plate was read with a standard ELISA reader at $490 \mathrm{~nm}$. The quantity of antibody was measured in comparison with standard sample diluents.

Granzyme B ELISA. 1 $10^{6}$ natural killer cells harvested from above immunized mice were added to the 96 well microplate along with $5 \mu \mathrm{g} / \mathrm{ml}$ of AFP peptide containing $10 \%$ fetal bovine serum and 10 units $/ \mathrm{ml}$ of mouse interleukin (IL)-2 (PEPRO Tech ET Ltd.). After culturing at $37^{\circ} \mathrm{C}$ for $24 \mathrm{~h}$, granzyme $\mathrm{B}$ released by NK cells was measured using a mouse granzyme B ELISA kit (CSB-E08720m, Cusabio Biotech) according to manufacturer's instructions. Plates were counted on an ELISA reader at $490 \mathrm{~nm}$.

Cytotoxic T-lymphocyte (CTL) assays. BALB/C mice were immunized subcutaneously (s.c.) as described above. Two weeks after the last boost, $2.5 \times 10^{7}$ splenocytes were co-cultured with $5 \mu \mathrm{g} / \mathrm{ml}$ of AFP peptide containing 10\% fetal bovine serum, 10 units $/ \mathrm{ml}$ of mouse interleukin (IL)-2 in RPMI 1640 supplemented with $10 \% \mathrm{FCS}$ at $37^{\circ} \mathrm{C}$ in $5 \% \mathrm{CO}_{2}$. After 5 days of stimulation, the viable splenocytes were removed and used as effector cells, and the H22 cells or LLC cells were used as target cells. The Non-Radioactive Cytotoxicity Lactate Dehydrogenase (LDH) release assay kit (Promega, U.S.A.) was used to measure the cytotoxicity of effector cells against H22 or LLC tumor cells in the ratios of 10:1,20:1 and 40:1, according to the manufacturer's protocol. Specific lysis was calculated according to the formula: percent specific lysis $=[$ experimental release value - effector spontaneous release value - target spontaneous release value)/(target maximum release value - target spontaneous release value) $] \times 100$. Results shown are representative of experiments repeated three times.

$\mathrm{CD8}^{+} \mathrm{T}$ cell depletion $\mathrm{CTL}$ assays. To confirm $\mathrm{CD}^{+} \mathrm{T}$ cell response, a separate set of immunized mice were sacrificed and spleens were collected. $\mathrm{CD}^{+} \mathrm{T}$ cells were depleted from spleen suspensions with anti-CD8 ${ }^{+}$Micro-Beads. The remaining splenocytes were co-cultured with $5 \mu \mathrm{g} / \mathrm{ml}$ of AFP peptide containing $10 \%$ fetal bovine serum, 10 units $/ \mathrm{ml}$ of mouse interleukin (IL)-2 in RPMI 1640 supplemented with 10\% FCS at $37^{\circ} \mathrm{C}$ in $5 \% \mathrm{CO} 2$. After 5 days of stimulation, the splenocytes 


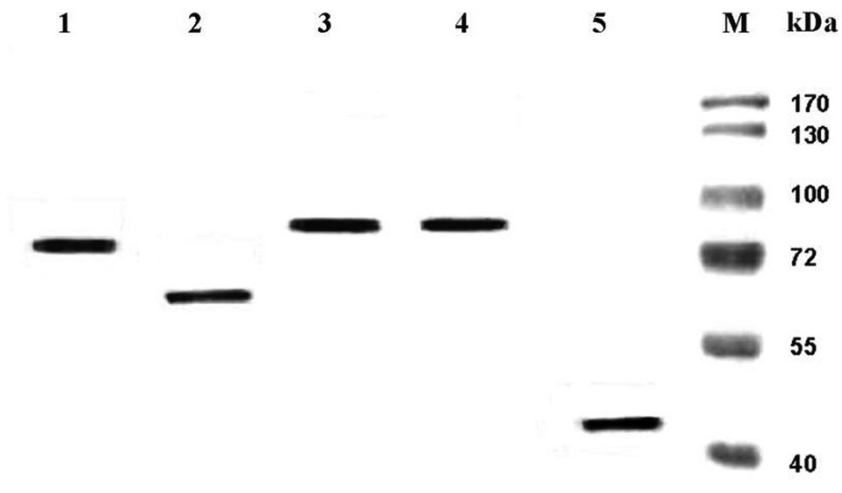

Figure 1. Analysis of purified HSP72/AFP-P by Western blot. The identity of the purified protein was verified by Western blot with polyclonal antibodies. The relative molecular weights of HSP72, AFP, HSP72/AFP-P and $\beta$-actin were $\sim 72,69,75$ and $42 \mathrm{kDa}$, respectively. Lane 1, purified HSP72 with HSP72 antibody; Lane 2, purified AFP with AFP antibody; Lane 3, purified HSP72/AFP-P complex with HSP72 antibody; Lane 4, purified HSP72/AFP-P complex with AFP antibody; Lane 5, $\beta$-actin; M: protein molecular weight markers.

were used as effector cells and co-cultured with the $\mathrm{H} 22$ cells as described above. Specific lysis was calculated according to the formula: percent specific lysis $=(($ experimental release value-effector spontaneous release value-target spontaneous release value)/(target maximum release value-target spontaneous release value) $) \times 100$. Results shown are representative of experiments repeated three times.

Natural killer cell depletion CTL assays. To determine natural killer cell response, another separate set of immunized mice were sacrificed and spleens were collected. Natural killer cells were depleted from spleen suspensions with anti-NKG2D Micro-Beads. The remaining splenocytes were cocultured with $5 \mu \mathrm{g} / \mathrm{ml}$ of AFP peptide containing $10 \%$ fetal bovine serum, 10 units/ml of mouse interleukin (IL)-2 in RPMI 1640 supplemented with $10 \%$ FCS at $37^{\circ} \mathrm{C}$ in $5 \%$ $\mathrm{CO} 2$. After 5 days of stimulation, the splenocytes were used as effector cells and co-cultured with the $\mathrm{H} 22$ cells as described above. Specific lysis was calculated according to the formula: percent specific lysis $=(($ experimental release value - effector spontaneous release value-target spontaneous release value)/ (target maximum release value-target spontaneous release value) $\times 100$. Results shown are representative of experiments repeated three times.

$\mathrm{CD8}^{+} \mathrm{T}$ cell and natural killer cell depletion CTL assays. To further verify whether $\mathrm{CD}^{+} \mathrm{T}$ cell and natural killer cell concurrently participate in the anti-tumor immunity, a separate set of immunized mice were sacrificed and spleens were collected. $\mathrm{CD}^{+} \mathrm{T}$ cell and natural killer cells were depleted from spleen suspensions with anti-CD $8^{+}$and anti-NKG2D Micro-Beads. The remaining splenocytes were cocultured with $5 \mu \mathrm{g} / \mathrm{ml}$ of AFP peptide containing 10\% fetal bovine serum, 10 units/ml of mouse interleukin (IL)-2 in RPMI 1640 supplemented with $10 \% \mathrm{FCS}$ at $37^{\circ} \mathrm{C}$ in $5 \% \mathrm{CO} 2$. After 5 days of stimulation, the splenocytes were used as effector cells and co-cultured with the $\mathrm{H} 22$ cells as described above. Specific lysis was calculated according to the formula: percent specific lysis $=(($ experimental release value-effector spontaneous release value-target spontaneous release value)/(target maximum release value-target spontaneous release value) $) \times 100$. Results shown are representative of experiments repeated three times.

In vivo tumor therapeutic experiments. To test the ability of HSP72/AFP-P conjugated vaccine to inhibit the growth of established tumors, BALB/C mice in each group were injected subcutaneously in the left flank with $5 \times 10^{5} \mathrm{H} 22$ cells per mouse on day 0 , and then injected subcutaneously in the right flank with different vaccine on day 3,10 , and 17 as described above. H22 tumor cells were washed after enzymatic digestion and resuspended in $0.2 \mathrm{ml}$ of PBS per animal, then injected s.c. into the left flank, while PBS was used as control. The tumor growth was monitored every day. Tumor size was measured in two dimensions with calipers every 3 days one week after tumor inoculation. At each time point, tumor size was determined by measuring the tumor width (a) and length (b). Tumor volume was calculated using the formula: $\mathrm{V}=\left(\mathrm{a}^{2} \mathrm{~b}\right) / 2$. Tumor size measurements were performed by the mean value of each group and performed in duplicate to confirm the results. Percentage of tumor-free mice was recorded and the survival of mice was monitored for eight weeks from the day of tumor challenge.

Statistical analysis. All statistical analyses were carried out using the SPSS 13.0 statistical software package.The frequencies of IFN- $\gamma$-producing splenic cells were valued using $\chi^{2}$ test. The Student's $t$ test was performed to analyze the significance of differences between final tumor volumes of different groups of animals. $P<0.05$ was considered statistically significant.

\section{Results}

Identification of purified HSP72/AFP-P complex. To obtain purified HSP72/AFP-P complex, a sequential polyclonal antibody-affinity chromatography was performed. The non-conjugated AFP peptide and HSP72 were eluted by HSP72 polyclonal antibody-affinity chromatography and AFP polyclonal antibody-affinity chromatography, respectively. The purification of HSP72/AFP-P complex was confirmed by SDS-PAGE and Western blot (Fig. 1). The purified HSP72/ AFP-P complex was identified by HSP72 polyclonal antibody and AFP polyclonal antibody via Western blot. The results confirmed that HSP72/AFP-P complex was constructed and produced successfully.

Prime-boost vaccines generate AFP-specific $\mathrm{CD8}^{+} \mathrm{T}$ cells and natural killer cells in vivo. Since cytotoxic T-lymphocytes (CTLs) have been known to play a critical role in tumor immunity, we examined AFP-specific $\mathrm{CD} 8^{+} \mathrm{T}$ cell frequency after HSP72/AFP-P vaccination by ELISPOT assays. Two weeks after the last immunization, $\mathrm{CD} 8^{+} \mathrm{T}$ cells were captured and stimulated with AFP peptide. As shown in Table 1, immuniza- 
tion of BALB/C mice with HSP72/AFP-P conjugated vaccine elicited much stronger $\mathrm{CD} 8^{+} \mathrm{T}$ cells responses than those with AFP-P immunization, whereas a vaccination with HSP72 or AFP-P alone produced a week response. Four hundred sixty eight IFN- $\gamma$ spot-forming cells specific for AFP protein were detected per $1 \times 10^{6} \mathrm{CD}^{+} \mathrm{T}$ cells derived from the HSP72/ AFP-P vaccinated mice, compared with only 15 of those derived from AFP-P vaccinated mice. Therefore, the numbers of IFN- $\gamma$-producing $\mathrm{CD}^{+} \mathrm{T}$ cells in the splenocytes from mice immunized with HSP72/AFP-P were 30 times more than those from mice immunized with the HSP72 or AFP-P $(P<$ 0.01). Our data suggested that HSP72/AFP-P vaccine elicited significantly stronger AFP-specific $\mathrm{CD}^{+} \mathrm{T}$ cells response compared with the other vaccinated groups.

To determine whether natural killer cells participated in the specific anti-tumor response, we measured the granzyme $B$ released from the natural killer cells harvested from mice immunized by different vaccines. As shown in Table 1, HSP72/ AFP-P immunized mice produced higher concentration of granzyme B than those immunized with AFP-P, HSP72 or PBS groups. The concentration of granzyme $B$ in natural killer cells from mice immunized with HSP72/AFP-P were 15 times higher than that from mice immunized with HSP72 or AFP-P alone $(P<0.01)$. The results indicated that HSP72/AFP-P vaccine induced significantly higher AFP-specific natural killer cells response compared with other vaccine groups.

HSP72/AFP-P induced AFP-specific antibodies in vivo. The quantity of anti-AFP antibodies in the sera of the vaccinated mice was determined by ELISA. Fourteen days after the last vaccination, HSP72/AFP-P immunized mice produced significant higher level of AFP-specific antibody than those immunized with AFP-P, HSP72 or PBS. The concentration of anti-AFP antibody from mice immunized with HSP72/ AFP-P was 15 times higher than that from mice immunized with AFP-P $(P<0.01)$ (Table 1). This result suggested that the conjugated vaccines potently induced specific antibody responses. On the contrary, the concentration of anti-HSP72 antibody from mice immunized with HSP72/AFP-P was not higher than that from mice immunized with HSP72, AFP-P or PBS $(P>0.05)$ (Table 1$)$.

HSP72/AFP-P significantly primes potent AFP-specific $\mathrm{CD8}^{+} \mathrm{T}$ cell and natural killer cell responses. It has been demonstrated previously that AFP/HSP70 reconstructed vaccines are able to induce the regression of AFP-expressing tumors in mice through either prophylactic or therapeutic treatment $[10,17]$. To examine whether HSP72/AFP-P vaccination is able to better prime AFP-specific $\mathrm{CD}^{+} \mathrm{T}$ cells and natural killer cells than HSP72 or AFP-P immunization, we performed in vitro lymphocyte cytotoxicity assays of splenocytes isolated from mice immunized with HSP72/ AFP-P, HSP72, AFP-P or PBS respectively. Splenocytes were harvested two weeks after immunization and restimulated in vitro with AFP peptide. Viable screened effector cells were assessed for cytotoxic activity against $\mathrm{H} 22$ cells. As shown in Fig. 2, effector cells from mice immunized with HSP72/ AFP-P showed significantly stronger cytolytic effects on $\mathrm{H} 22$ target cells than those from mice vaccinated with HSP72, AFP-P or PBS $(P<0.01)$ (Fig. $2 A)$. In addition, this cytolytic activity was specific for $\mathrm{H} 22$ cells, not for LLC cells $(P<0.01)$ (Fig. 2B). Our results also indicated that the cross linkage of AFP peptide to HSP72 was required for the enhancement of specific $\mathrm{CD}^{+} \mathrm{T}$ cell and natural killer cell activity, since the administration of AFP-P or HSP72 only exhibited much lower cytolytic activity. In contrast, splenocytes from the PBS control and empty group showed very low level of target cell lysis.

To elucidate whether $\mathrm{CD} 8^{+} \mathrm{T}$ cells or natural killer cells participated in the cytotoxic effect on $\mathrm{H} 22$ tumor cells, CD8 ${ }^{+}$ $\mathrm{T}$ cell and natural killer cell depletion assay were performed. After $\mathrm{CD} 8^{+} \mathrm{T}$ cells or natural killer cells depletion, the remaining splenocyte effector cells from mice vaccinated with HSP72/ AFP-P showed lower cytolytic effects on H22 target cells, especially after $\mathrm{CD} 8^{+} \mathrm{T}$ cells depletion. While both $\mathrm{CD} 8^{+} \mathrm{T}$ cell and natural killer cell were depleted, the remaining splenocytes demonstrated a very lower cytolytic effects on target cells. The splenocytes from mice vaccinated with HSP72, AFP-P or PBS alone did not show significant difference in cytolytic activity $(P>0.05)$ (Fig. 2C, 2D, 2E). Our results indicated that both $\mathrm{CD} 8^{+} \mathrm{T}$ cells and natural killer cells concurrently participated in the specific cytolytic activity against $\mathrm{H} 22$ tumor cells via HSP72/AFP-P immunization.

HSP72/AFP-P vaccination induced therapeutic immunity against $\mathrm{H} 22$ tumors. To further investigate the AFP-specific CTL response elicited by HSP72/AFP-P complex, we examined the therapeutic effect of the conjugated protein vaccines on inducing regression of pre-existing AFP-expressing $\mathrm{H} 22$

Table 1. Immunological parameters of mice immunized with therapeutic peptide vaccines.

\begin{tabular}{|c|c|c|c|c|c|}
\hline Groups & Empty & PBS & AFP-P & HSP72 & HSP72/AFP-P \\
\hline $\operatorname{Spots}^{a}\left(\times 10^{6}\right.$ cells $)$ & $15.54 \pm 7.26$ & $15.67 \pm 7.52$ & $15.81 \pm 8.12^{\#}$ & $16.13 \pm 8.37^{s}$ & $468.5 \pm 18.41^{* *}$ \\
\hline Granzyme $B^{b}(\mu \mathrm{g} / \mathrm{ml})$ & $8.37 \pm 2.26$ & $8.42 \pm 2.65$ & $8.46 \pm 2.84^{\#}$ & $8.52 \pm 2.73^{s}$ & $128.75 \pm 9.34^{\ddagger^{*}}$ \\
\hline $\operatorname{AFP} \operatorname{Abs}^{c}(\mu \mathrm{g} / \mathrm{ml})$ & $0.46 \pm 0.25$ & $0.47 \pm 0.22$ & $0.49 \pm 0.18^{\#}$ & $0.50 \pm 0.23^{\mathrm{s}}$ & $7.59 \pm 2.24^{\ddagger^{*}}$ \\
\hline $\operatorname{HSP}_{2} \mathrm{Abs}^{\mathrm{d}}(\mu \mathrm{g} / \mathrm{ml})$ & $0.48 \pm 0.19$ & $0.49 \pm 0.25$ & $0.50 \pm 0.22^{*}$ & $0.52 \pm 0.31^{\mathrm{s}}$ & $0.53 \pm 0.24^{\ddagger^{*}}$ \\
\hline
\end{tabular}

${ }^{\mathrm{a} H S P 72}$-specific IFN- $\gamma$-secreting CD8 ${ }^{+} \mathrm{T}$ cells; ${ }^{\mathrm{b}}$ Granzyme B released from natural killer cells; ${ }^{\mathrm{c}} \mathrm{AFP}-\mathrm{P}$ specific antibodies in mice; ${ }^{\mathrm{d}} \mathrm{HSP} 72$-specific antibodies in mice

${ }^{*} P>0.05$, vs empty group; ${ }^{\$} P>0.05$, vs empty group; ${ }^{*} P<0.01$, vs empty group; ${ }^{*} P<0.01$, vs $\mathrm{HSP} 72$ group. 

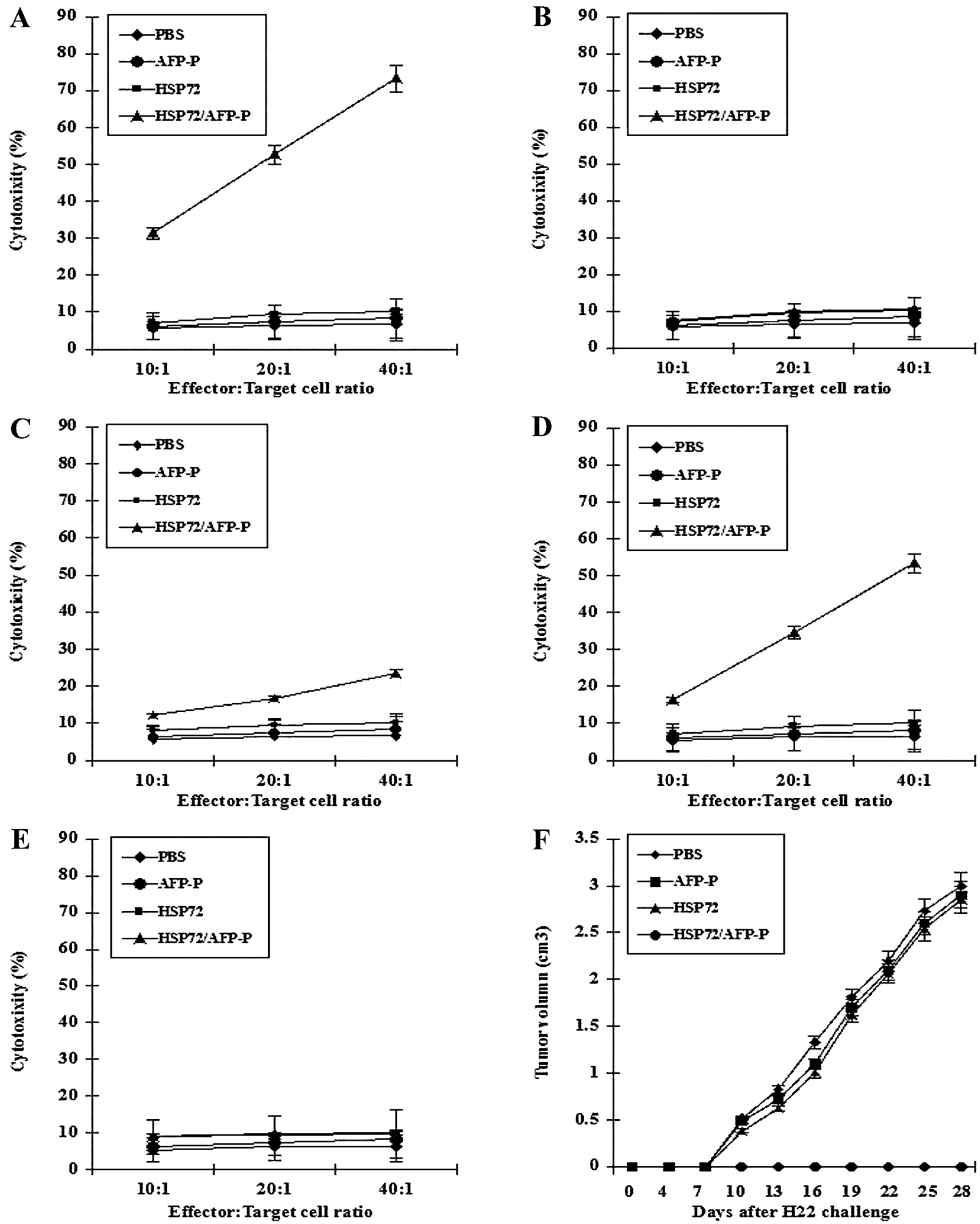

Figure 2. HSP72/AFP-P complex primed the strongest AFP-specific $\mathrm{CD8}^{+} \mathrm{T}$ cell and natural killer cell responses.

AFP-specific cytolytic activity was assayed against target cells at 10:1, 20:1 and 40:1 E/T (effector/target) ratios for H22 cells (A), LLC cells (AFP-negative control) (B), $\mathrm{CD8}^{+} \mathrm{T}$ cells depleted splenocytes $(\mathrm{C})$, natural killer cells depleted splenocytes (D), both CD8 ${ }^{+} \mathrm{T}$ cells and natural killer cells depleted splenocytes (E). Therapeutic immunization of mice with HSP72/AFP-P enhanced the anti-tumor immunity more significantly than immunization with AFP-P, HSP72 or PBS $(P<0.01)(F)$. 
tumors in vivo. In these studies, female BALB/C mice were injected with $5 \times 10^{5} \mathrm{H} 22$ cells s.c. in the left flank, and then vaccinated s.c. in the right flank with HSP72/AFP-P, AFP-P, HSP72 or PBS (100 $\mu 1 /$ mouse) on days 3, 10 and 17 . The growth of tumor was monitored for about 4 weeks since day 7 post tumor inoculation. All mice immunized with HSP72/AFP-P had tumor-free survival for more than 60 days. In contrast, mice receiving HSP72 or AFP-P developed tumor growth within 10 days after tumor challenge, indicating that cross linkage between AFP-P and HSP72 is essential for effective therapy. For comparison, the mean tumor volumes from various groups of mice were shown in Fig. 2F. Mice immunized with HSP72 or AFP-P alone demonstrated significantly higher average tumor volume than mice immunized with HSP72/AFP-P $(P$ $<0.05)$. There was a statistically significant difference in the therapeutic effect of $\mathrm{H} 22$ tumor between HSP72/AFP-P and AFP-P vaccinated group $(P<0.01)$. However, there was no statistically difference in the tumor mass among the groups immunized with AFP-P, HSP72 or PBS control group. Different vaccinations greatly influenced the survival of mice. The mice immunized with AFP-P or HSP72 all died before day 49 and all mice immunized with HSP72/AFP-P still survived at day 60, whereas all mice treated with PBS demised before day 35. These data suggested that HSP72/AFP-P immunization significantly reduced tumor size and prolonged the survival time of the tumor-bearing mice than AFP-P immunization alone, indicating that the vaccination of HSP72/AFP-P exerted a desirable therapeutic effect against $\mathrm{H} 22$ tumor cells in vivo. In summary, these results showed that vaccination with HSP72/ AFP-P could eradicate previously inoculated AFP-expressing tumor cells in mice and inhibit the growth of tumors, exhibiting a potent anti-tumor activity in vivo.

\section{Discussion}

Recent studies on the immunodominant epitopes of AFP have provided a solution to the obstacle of HCC immunotherapy. AFP is produced at low serum levels after birth throughout life. The majority of human HCC overexpress the oncofetal antigen AFP, a glycoprotein of Mr 64,000 72,000. Despite being exposed to high plasma levels of this oncofetal protein during embryonic development, body still displays a low immunity to it $[18,19]$. Butterfiel found that four peptides of human AFP were processed and presented in the context of HLA-A0201, which could be recognized by the human $\mathrm{T}$ cell repertoire and generated AFP-specific CTL in human T cell cultures [6]. It was also found that murine immune system could generate T-cell responses to this oncofetal antigen. Therefore, AFP may be a promising for immunotherapy. However, AFP immunization alone still results in a low level of specific immune response and poorly reproducible protective immunity $[4,5]$. Therefore, enhancing host's active immunity to AFP is currently an actively sought strategy for HCC therapy.

In the present study, we developed a novel strategy to induce antitumor immunity by conjugating AFP peptide to HSP72 via glutaraldehyde cross-linking. We found that the vaccine could elicit strong AFP-specific T-cell responses and produce a distinct protective effect against AFP-producing tumor. The study showed that HSP72/AFP-P could produce relatively strong $\mathrm{CD} 8^{+} \mathrm{T}$ cell and natural killer cell responses, indicating that AFP-specific $\mathrm{CD}^{+} \mathrm{T}$ cell and natural killer cell responses greatly contributed to the anti-tumor effects of HSP72/AFP-P vaccines. It is of interest to note that the cross-linking protein vaccine provoked not only considerable stability of immunoprotection, but also a detectable level of anti-AFP antibody. High level of anti-AFP antibody was detected from HSP72/ AFP-P immunized mice. Currently, the mechanism of antibodydependent immune cell function is still not well defined. We don't know whether humoral immunity mediated by B cells plays a primary role in anti-tumor effect, but we speculate that anti-AFP antibody was likely to neutralize the AFP antigen or mediate the antibody-dependent immune cell cytotoxicity.

Protein-based vaccines have become an attractive approach to generate antigen-specific immunotherapy because of their simplicity, safety, efficacy and capacity for repeated administration. Protein vaccines generate effective cytotoxic $\mathrm{T}$ lymphocyte (CTL) and antibody responses by engaging antigen presenting cells (APC) to stimulate $\mathrm{CD} 4^{+}$and $\mathrm{CD} 8^{+}$ $T$ cells. Protein vaccines can be easily prepared on a large scale with high purity and stability and can also be repeatedly given to the same patient safely and effectively $[20,21]$. These features make protein vaccines a potentially attractive approach for cancer immunotherapy. However, it is critical to increase the potency of protein vaccines. Since tumor antigens are weakly immunogenic, researchers are currently focusing on conjugating versatile immunostimulatory molecules to the therapeutic cancer vaccines. Various HSP-based vaccine strategies have been described to enhance fusion vaccine immunogenicity. In early studies from our group, we constructed an eukaryotic expression vector containing the molecular chaperon-HSP70 and AFP fragments, then primed mice with the genetic vaccine, which produced a robust strong protective immunity [10]. Another research group also confirmed that the linkage of HSP70 to target antigens dramatically enhanced the potency of AFP fusion protein vaccines [17]. Therefore, an innovative approach that combines HSP with tumor antigen will probably generate more potent antitumor effect. HSP72 is a member of heat shock protein family which has been shown to act as a potent adjuvant to enhance antigen-specific tumor immunity and innate immunity $[22,23]$. The use of HSP72 conjugated antigen vaccines represents a promising approach for enhancing antigen-specific $\mathrm{T}$ cell-mediated immune responses as well as humoral responses for cancer vaccine development $[24,25]$.

It was reported that HSPs could increase the risk of autoimmunity due to cross-reactive T-lymphocytes primed by the HSP vaccines [26-28]. However, our work showed that vaccination with HSP72/AFP-P protein vaccine did not result in pathologic changes in the major organs of mice. We also haven't detected the anti-HSP72 antibody from HSP72/AFP-P or HSP72 immunized mice. It may be an explanation that some 
symptoms of autoimmune disease haven't been induced in the experiment and clinical trial.

In this study, we described a novel AFP peptide-based immunization strategy based on the vaccine constructed by cross-linking HSP72 and AFP epitope peptide. Our data demonstrated that HSP72/AFP-P vaccination could elicit strong AFP-specific $\mathrm{CD}^{+} \mathrm{T}$ cell immune responses, and induce regression of the established $\mathrm{H} 22$ tumor. One of the potential explanations is that linkage of HSP72 to AFP peptide may lead to enhanced stimulation of AFP-specific $\mathrm{CD}^{+} \mathrm{T}$ cells and natural killer cells in vivo via the so-called "cross-priming" mechanism [29,30]. Cross-priming is a complex process which requires enzymatic processing of the exogenous antigen through different intracellular compartments [29]. Dependent on the characteristics of the exogenous antigen and the capacity of antigen presenting cells (APCs), cross-priming may involve different process [30]. It is well established that complexes of HSP-chaperoned synthetic peptides can direct peptides into the MHC class-I antigen-presentation pathways of APCs. By this process, chaperone-peptide complexes are thought to elicit tumor-directed CD8 ${ }^{+}$CTL $[31,32]$. In addition, HSPs can also use different receptors to mediate their effects [33-35]. It is conceivable that HSP72/AFP-P could interact with various receptors on APCs, leading to antigen cross-priming. The "cross-priming" mechanism may provide an explanation for the observed enhancement of AFP-specific $\mathrm{CD}^{+} \mathrm{T}$ cell response in mice vaccinated with HSP72/AFP-P, as compared with mice vaccinated with HSP72 or AFP-P alone. It has been confirmed that HSP70 could enhance NK cell cytotoxic responses via interacting with the NKG2D receptor [36,37]. NK cells provide the body's first line of defense against transformed cells by releasing cytotoxic granules, producing cytokines and causing cytotoxicity. Granzyme B is a serine protease stored in the cytoplasmic granules of NK cells. When granzyme B is actively secreted into the interspace between the cytotoxic cell and the target cell, granzyme B works along with perforin to induce apoptosis in target cells by forming transmembrane pores and through cleaving of effector caspases [38-40]. Our study revealed that HSP72/ AFP-P vaccine elicited significant cytolytic activity of NK cells against $\mathrm{H} 22$ target cells through granzyme $\mathrm{B}$ release.

In conclusion, our results indicate that HSP72/AFP-P vaccine can generate an impressive antitumor effect against AFP-expressing murine tumors through enhancing the immune responses mediated by AFP-specific $\mathrm{CD} 8^{+} \mathrm{T}$ cells and natural killer cells. Therefore, the tumor vaccine by crosslinking tumor antigen and HSP72 is a promising approach for cancer therapy which may be potentially applied to other cancers with known tumor-specific antigens.

Acknowledgements: The work was supported by National Natural Science Foundation of China (No.81172135, 81310108008), Key Project of Ministry of Education of China (No.205002) and Scientific Research Program of Shaanxi Provincial Education Department (No.2007JK233, 14JS025).

\section{References}

[1] SCHAFER DF, SORRELL MF. Hepatocellular carcinoma. Lancet 1993; 353: 1253-1257.

[2] TANG ZY. Hepatocellular carcinoma--cause, treatment and metastasis. World J Gastroenterol 2001; 7: 445-454.

[3] WONG R, FRENETTE C. Updates in the management of hepatocellular carcinoma. Gastroenterol Hepatol (NY) 2011; 7: 16-24.

[4] HANKE P, RABE C, SERWE M, BOHM S, PAGENSTECHER $\mathrm{C}$, et al. Cirrhotic patients with or without hepatocellular carcinoma harbour AFP-specific T-lymphocytes that can be activated in vitro by human alpha-fetoprotein. Scand J Gastroenterol 2002; 37: 949-955. http://dx.doi. org/10.1080/003655202760230928

[5] SAEKI A, NAKAO K, NAGAYAMA Y, YANAGI K, MATSUMOTO K, et al. Diverse efficacy of vaccination therapy using the alpha-fetoprotein gene against mouse hepatocellular carcinoma. Int J Mol Med 2004; 13: 111-116.

[6] BUTTERFIELD LH, KOH A, MENG W, VOLLMER CM, RIBAS A, et al. Generation of human T-cell responses to an HLA-A2.1-restricted peptide epitope derived from alphafetoprotein. Cancer Res 1999; 59: 3134-3142.

[7] MENG WS, BUTTERFIELD LH, RIBAS A, HELLER JB, DISSETTE VB, et al. Fine specificity analysis of an HLAA2.1-restricted immunodominant $\mathrm{T}$ cell epitope derived from human alpha-fetoprotein. Mol Immunol 2000; 37: 943-950. http://dx.doi.org/10.1016/S0161-5890(01)00017-7

[8] GRIMM CF, ORTMANN D, MOHR L, MICHALAK S, KROHNE TU, et al. Mouse alpha-fetoprotein-specific DNAbased immunotherapy of hepatocellular carcinoma leads to tumor regression in mice. Gastroenterology 2000; 119: 1104-1112. http://dx.doi.org/10.1053/gast.2000.18157

[9] HANKE P, SERWE M, DOMBROWSKI F, SAUERBRUCH T, CASELMANN WH. DNA vaccination with AFP-encoding plasmid DNA prevents growth of subcutaneous AFP-expressing tumors and does not interfere with liver regeneration in mice. Cancer Gene Ther 2002; 9: 346-355. http://dx.doi. org/10.1038/sj.cgt.7700445

[10] WANG XP, LIU GZ, SONG AL, LI HY, LIU Y. Antitumor immunity induced by DNA vaccine encoding alpha-fetoprotein/heat shock protein 70. World J Gastroenterol 2004; 10: 3197-3200.

[11] MENG WS, BUTTERFIELD LH, RIBAS A, DISSETTE VB, HELLER JB, et al. alpha-Fetoprotein-specific tumor immunity induced by plasmid prime-adenovirus boost genetic vaccination. Cancer Res 2001; 61: 8782-8786.

[12] WALKER KB, KEEBLE J, COLACO C. Mycobacterial heat shock proteins as vaccines: a model of facilitated antigen presentation. Curr Mol Med 2007; 7: 339-350. http://dx.doi. org/10.2174/156652407780831575

[13] SINGH-JASUJA H, HILF N, SCHERER HU, ARNOLDSCHILD D, RAMMENSEE HG, et al. The heat shock protein gp96: a receptor-targeted cross-priming carrier and activator of dendritic cells. Cell Stress Chaperones 2000; 5: 462-470. http://dx.doi.org/10.1379/1466-1268(2000) $005<0462:$ THSPGA $>2.0$. CO;2 
[14] BINDER RJ, HAN DK, SRIVASTAVA PK. CD91: a receptor for heat shock protein gp96. Nat Immunol 2000; 1: 151-155. http://dx.doi.org/10.1038/77835

[15] LIU B, YE D, SONG X, ZHAO X, YI L, et al. A novel therapeutic fusion protein vaccine by two different families of heat shock proteins linked with HPV16 E7 generates potent antitumor immunity and antiangiogenesis. Vaccine 2008; 26: 1387-1396. http://dx.doi.org/10.1016/j.vaccine.2007.12.034

[16] ZONG J, PENG Q, WANG Q, ZHANG T, FAN D, XU X. Human HSP70 and modified HPV16 E7 fusion DNA vaccine induces enhanced specific CD8+ T cell responses and antitumor effects. Oncol Rep 2009; 22: 953-961.

[17] LAN YH, LI YG, LIANG ZW, CHEN M, PENG ML, et al. A DNA vaccine against chimeric AFP enhanced by HSP70 suppresses growth of hepatocellular carcinoma. Cancer Immunol Immunother 2007; 56: 1009-1016. http://dx.doi.org/10.1007/ s00262-006-0254-3

[18] DEUTSCH HF. Chemistry and biology of a-fetoprotein. Adv Cancer Res 1991; 56: 253-311. http://dx.doi.org/10.1016/ S0065-230X(08)60483-2

[19] GOLDENBERG DM, KIM EE, DELAND F, SPREMULLI E, NELSON MO, et al. Clinical studies on the radioimmunodetection of tumors containing alpha-fetoprotein. Cancer 1980; 45: 2500-2505. http://dx.doi.org/10.1002/1097-0142(19800515)45:10<2500::AID-CNCR2820451006>3.0.CO;2-J

[20] DONNELLY JJ, ULMER JB, SHIVER JW, LIU MA. DNA vaccines. Annu Rev Immunol 1997; 15: 617-648. http://dx.doi. org/10.1146/annurev.immunol.15.1.617

[21] GURUNATHAN S, KLINMAN DM, SEDER RA. DNA vaccines: immunology, application, and optimization. Annu Rev Immunol 2000; 18: 927-974. http://dx.doi.org/10.1146/ annurev.immunol.18.1.927

[22] CHALMIN F, LADOIRE S, MigNOT G, VINCENT J, BRUCHARD M, et al. Membrane-associated Hsp72 from tumor-derived exosomes mediates STAT3-dependent immunosuppressive function of mouse and human myeloid-derived suppressor cells. J Clin Invest 2010; 120: 457-471. http:// dx.doi.org/10.1172/jci40483

[23] GONG J, ZHANG Y, DURFEE J, WENG D, LIU C, et al. A heat shock protein 70-based vaccine with enhanced immunogenicity for clinical use. J Immunol 2010; 184: 488-496. http://dx.doi.org/10.4049/jimmunol.0902255

[24] MYERS AL, KREWET JA, SHAH MR. Tumor immunity and prolonged survival following combined adenovirus-HSP72 and CEA-plasmid vaccination. Vaccine 2005; 23: 3565-71. http://dx.doi.org/10.1016/j.vaccine.2005.01.148

[25] WANG XP, LIN HP, WANG QX, GU Y. Specific antitumor immunity induced by cross-linking complex heat shock protein 72 and alpha-fetoprotein. Cancer Biother Radiopharm 2012; 27: 189-197. http://dx.doi.org/10.1089/cbr.2011.1135

[26] YOUNG RA. Stress proteins and immunology. Annu Rev Immunol 1990; 8: 401-20. http://dx.doi.org/10.1146/annurev. iy.08.040190.002153

[27] STEINHOFF U, BRINKMANN V, KLEMM U, AICHELE P, SEILER P, et al. Autoimmune intestinal pathology induced by hsp60-specific CD8 T cells. Immunity 1999; 11: 349-358. http://dx.doi.org/10.1016/S1074-7613(00)80110-7
[28] ZÜGEL U, KAUFMANN SH. Role of heat shock proteins in protection from and pathogenesis of infectious diseases. Clin Microbiol Rev 1999; 12: 19-39.

[29] SRIVASTAVA P. Interaction of heat shock proteins with peptides and antigen presenting cells: chaperoning of the innate and adaptive immune responses. Annu Rev Immunol 2002; 20: 395-425. http://dx.doi.org/10.1146/annurev. immunol.20.100301.064801

[30] LI Z, MENORET A, SRIVASTAVA P. Roles of heat-shock proteins in antigen presentation and cross-presentation. Curr Opin Immunol 2002; 14: 45-51. http://dx.doi.org/10.1016/ $\underline{\text { S0952-7915(01)00297-7 }}$

[31] HAUSER H, SHEN L, GU QL, KRUEGER S, CHEN SY. Secretory heat-shock protein as a dendritic cell-targeting molecule: a new strategy to enhance the potency of genetic vaccines. Gene Ther 2004; 11: 924-932. http://dx.doi.org/10.1038/ sj.gt. 3302160

[32] BINDER RJ, SRIVASTAVA PK. Peptides chaperoned by heatshock proteins are a necessary and sufficient source of antigen in the cross-priming of CD8+ T cells. Nat Immunol 2005; 6: 593-599. http://dx.doi.org/10.1038/ni1201

[33] BASU S, BINDER RJ, RAMALINGAM T, SRIVASTAVA PK. CD91 is a common receptor for heat shock proteins gp96, hsp90, hsp70, and calreticulin. Immunity 2001; 14: 303-313. http://dx.doi.org/10.1016/S1074-7613(01)00111-X

[34] BECKER T, HARTL FU, WIELAND F. CD40 an extracellular receptor for binding and uptake of Hsp70-peptide complexes, J Cell Biol 2002; 158: 1277-85. http://dx.doi.org/10.1083/ jcb.200208083

[35] DELNESTE Y, MAGISTRELLI G, GAUCHAT J, HAEUW J, AUBRY J, et al. Involvement of LOX-1 in dendritic cellmediated antigen cross-presentation. Immunity 2002; 17: 353-362. http://dx.doi.org/10.1016/S1074-7613(02)00388-6

[36] BOTTGER E, MULTHOFF G, KUN JF, ESEN M. Plasmodium falciparum-infected erythrocytes induce granzyme B by NK cells through expression of host-Hsp70. PLoS One 2012; 7: e33774. http://dx.doi.org/10.1371/journal. pone. 0033774

[37] LV LH, WAN YL, LIN Y, ZHANG W, YANG M, et al. Anticancer drugs cause release of exosomes with heat shock proteins from human hepatocellular carcinoma cells that elicit effective natural killer cell antitumor responses in vitro. J Biol Chem 2012; 287: 15874-15885. http://dx.doi.org/10.1074/jbc. M112.340588

[38] LORD SJ, RAJOTTE RV, KORBUTT GS, BLEACKLEY RC. Granzyme B: a natural born killer. Immunol Rev 2003; 193: 31-38. http://dx.doi.org/10.1034/j.1600-065X.2003.00044.x

[39] TRAPANI JA, SUTTON VR. Granzyme B: pro-apoptotic, antiviral, and antitumor functions. Curr Opin Immunol 2003; 15: 533-543. http://dx.doi.org/10.1016/S0952-7915(03)00107-9

[40] TAGLIA L, MATUSIAK D, BENYA RV. GRP-induced upregulation of Hsp72 promotes CD16+/94+ natural killer cell binding to colon cancer cells causing tumor cell cytolysis. Clin Exp Metastasis 2008; 25: 451-463. http://dx.doi.org/10.1007/ $\underline{\text { s10585-008-9151-9 }}$ 